\title{
ECONOMIC PERFORMANCE ASSESSMENT FOR AGRICULTURAL MARKET IN A REGION: EVIDENCE FROM RUSSIA
}

\author{
Vladimir Tretyak ${ }^{1, \mathrm{a}, *}$ \\ ${ }^{1}$ Russion Transport University, Department of Transport Economics \& Management, 9 Obraztsova, \\ Moscow, Russia, 127994 \\ ${ }^{\mathrm{a}} \mathrm{v} \_$tretyak@inbox.ru \\ *Corresponding author
}

Cite as: Tretyak, V. (2018). Ecnomic performance assessment for agricultural market in a region: Evidence from Russia, Ekonomicko-manazerske spektrum, 12(1), 83-93.

Available at: dx.doi.org/10.26552/ems.2018.1.83-93

\begin{abstract}
In recent years, Russian agricultural market has undergone rather important changes. Nowadays, there is a kind of euphoria concerning agricultural market. State support is planned, including significant investments, with the aim to stimulate its development. Still, literature analysis shows that efforts are supposed to concentrate mainly on the sphere of production. There is clear lack of attention to the level of technologies and equipment use, both in manufacturing and in turnover, i.e. in the post-harvest handling, long-term and operational storing of agricultural products, as well as in processing, product delivery to customers, preferably using highly specialized transportation, and in consumption waste disposal. This attention is necessary, otherwise the achieved production results will be destroyed due to low-tech turnover level, and the relationship between production and consumption will not give the expected results of the agricultural products market functioning. These facts has direct impact on the subjects operating in agricultural sector. Especially, on their economic performance, bankrupt or financial health as a whole. Economic performance of agricultural sector can lead to more efficient management of subject operating in this sector. In addition, it can bring more convenient prices of agricultural products for customers. In this article a hypothesis is discussed that the main issue should be not productivity growth or increase in production volume, but the level of technologies in agricultural production and bringing agricultural products to consumers, at all stages of the production-consumption relationship. It is therefore proposed to assess the market economic performance from the perspective of technological stages (tenors of technology) on which the creation and implementation of the product takes place. In this context, the expediency of the approach to the economic performance assessment for the agricultural market in a region is substantiated.
\end{abstract}

Keywords: economic performance, technological stages, state support, regional economic, domestic substitutes

JEL Classification: L140, L190, L520

\section{Introduction}

Efforts to increase food production are increasingly important as $60 \%$ more food will be needed by 2050 given current food consumption trends (FAO, 2012). There is a growing 
attention to the formation of balanced food systems which include "all the processes and infrastructure involved in population's food security, that is, the gathering/catching, growing, harvesting (production aspects), storing, processing, packaging, transporting, marketing, and consuming of food, and disposing of food waste (non-production aspects)" (Porter et al., 2014, p.490). Every part of the food system is of great importance, since only their balanced intersection allows achievement of synergy which is the main advantage of any system in contemporary network economy, stated by Baggio \& Sheresheva (2014).

Literature on the subject is a growing body of knowledge. In recent years, the number of papers devoted to the issues of agricultural market in emerging and developing economies has increased substantially, including discussion on the results of productivity-enhancing reforms, stated by Dabla-Norris et al. (2014), and Rodrigues Moreira et al. (2016), on the role of agricultural knowledge and innovation system in sustainable development and value creation, according to Abebe et al. (2013), and Trjascin (2013), on differentiation strategies and market opportunities for agricultural products in emerging markets, stated by Brenes, Montoya, \& Ciravegna (2014).

Kondratiev (1989) states still, performance assessment for agricultural markets in developing and transition economies remains problematic for academics and practitioners, stated by Bogdanov, Rodic, \& Vittuari (2017). Few economics and management theorists are engaged in research that helps to understand peculiarities of performance assessment in developing countries' agribusiness, argued by Bellon, Gotor \& Caracciolo (2015), and Anigbogu, Taiwo \& Nwachukwu (2016), as well as in agribusiness of East European economies, stated by Bojnec \& Latruffe (2013), and Hidefjall \& Backheden (2017). Further, there is a need to unveil the basic principles surrounding performance assessment for agricultural market in a region in case of emerging economy.

In order to fill some gaps within the field, this paper seeks to propose an approach to performance assessment for agricultural market in Russian region, taking local market of potatoes as a base for analysis, in accordance with Antonietti \& Marzucchi (2014), and Kifli \& Umami (2017). Nowadays, the literature on Russian agribusiness is scarce and focuses mainly on general issues of Russian agriculture during transition, agrued by Liefert \& Liefert (2012), and Schierhorn et al. (2014). In Russian local agricultural practice the issues of productivity growth and increase in production volume are most often discussed. At the same time, there is almost no attention to the level of technologies in agricultural production and bringing agricultural products to consumers, at all stages of the production-consumption relationship, - in spite of the fact that losses estimated by experts are huge, up to $40 \%$ of the reaped crop1. As an example, in accordance with the official data, in 2014 losses of potatoes made 2,066 million tons that is twice more than import volume (1.045 million tons), and nearly ten times more than cumulative domestic export ( 0.069 million tons), according to Liu et al. (2016). Therefore, the paper adds to the literature by broader appreciation of the key factors which have a significant impact upon regional agricultural market performance in the Russian emerging economy, with the special attention to the level of technologies and equipment use, both in manufacturing and in turnover.

The paper is organized around the following topics. Firstly, we focus on the issues of productivity and performance assessment, taking the structure-conduct-performance paradigm. Secondly, we give a brief overview of the methodology and research design. Thirdly, the results are presented which highlight the existing and potential opportunities of

${ }^{1}$ In Russia, the average potato yield is 13 tons per hectare, as compared with 14,5 tons in China, and 45 tons in Netherlands. http: //mi.aup.ru/res/33/562949984561433.html. 
agricultural market performance assessment in Russian regions. The paper is concluded with the section that summarizes the findings and proposes avenues of future research.

\section{Methodology}

Meanwhile, the concept of market performance is widely used in the economic science. In the field of industrial organization, it is widely recognized that industrial market performance is largely dependent on the current market structure, as well as the sellers and buyers behavior (structure-conduct-performance paradigm). Given the relatively high degree of uncertainty in the definition and understanding of market efficiency and performance, Caves (1992) and Holtermann (1974) identified four display modes of industry market performance:

The economy needs to be efficient, limited resources should be allocated so that they result in the greatest possible real income.

1. The economy needs to be efficient, limited resources should be allocated so that they result in the greatest possible real income,

2. The economy needs to be progressive, it should resupply production factors, improve quality and variety of products, as well as way in which of factors of production are organized,

3. The maximum employment level needs to be achieved in the economy, but not by virtue of the overabundant increase in the general price,

4. The economy needs to be fair, real income distribution between its members should satisfy their major requirements and reasonable expectations, at the same time rewarding their productive efforts.

Therefore, market performance is considered as the multi-factor phenomenon with no single indicator.

According to Scherer \& Ross (2002), and Grinciuc \& Bujor (2017), Schumpeter (1982) market performance manifestation may be considered as achieving at least the following objectives (the order not necessarily coincides with their importance):

A. Decisions about what, how much and how to produce should be effective for two reasons: limited resources should not be wasted, deciding what and how much to produce, must comply with quantitative and qualitative requirements of consumers,

B. Activities of the manufacturer should be progressive, they must take advantage of science and technology to increase output per unit of input, and provide consumers with the best new products. It also must be supported by long-term growth of real per capita income,

C. Manufacturers' activities should contribute to the full utilization of resources, especially labor. Or, at least, should not prevent the use of microeconomic tools for this purpose,

D. Income distribution must be fair (equitable). Justice is extremely difficult to determine. But it requires at least that the producers do not receive an income in excess of the level required for the reimbursement of services provided cost. To this end, to ensure reasonable price stability is desirable, since uncontrolled inflation distorts the distribution of income in the most negative way.

Though these goals do not have to follow each other, an industry performance is at best if all four objectives are achieved. However, even a simple measurement of the degree of these goals' achievement will be difficult, in accordance with Perez-Perez (1983), and Zinchuk et al. (2017). 


\section{Results}

In our study, we focus on the impact of the first two points related to scientific and technical progress, which is reflected in the change of technological stages ("tenors of technology"). At the same time, we regard employment and equity of income distribution as a present constant and examine market performance from the perspective of changing tenors of technology that increase the relationship of production and consumption.

In the literature, the term "tenor of technology" is perceived differently. From our point of view, this term should not be confused with the term "way of life", or with the term "socio economic structure". It is close to the term «technological stages» and thus should be understood as a complex of a certain level of technology, built on the basis of the one class of technical solutions using certain energy sources, appropriately qualified staff and adequate organization. Within a tenor of technology, a closed macro-production cycle is performed that includes production and obtaining primary resources, all stages of their conversion, as well as production of end products satisfying the corresponding type of public consumption. Each tenor of technology is a holistic and sustainable education, within which a closed cycle, including the production and reception of primary resources, all the stages of their processing and production of a set of end products that meet the appropriate type of public consumption.

Tenors of technology are present in any economy in certain combinations. The innovation process is manifested in the progressive replacement of old technological stages by new ones. Their role and significance is not the same. Among tenors of technology a leading one always stands out, called the dominant (main) tenor of technology. Therefore, modernization of the economy is generally a process of replacement of the existing dominating tenors of technology by other tenors that can meet more precisely the requirements of today.

One can assess the extent of any tenor of technology on the basis of the changes in the particular economy, in terms of the expenditures on technological innovation made by industrial production organizations, in accordance with the periodization of technological modes of economic activity, or on the basis of volume share of products manufactured using technologies of different tenors. It seems that the criterion should be monistic: say, the relationship is based on the relationship between instruments of labor and labor force in the presence of energy use form is the cornerstone.

We propose less detailed, but more consecutive periodization of technological stages. Regional gross domestic product is produced on the market. Its creation is performed based on technologies that can be attributed to the agricultural (pre-industrial), industrial and postindustrial technological stages based on the aforementioned criteria. Therefore, pre-industrial technological stages are included in the first (artisanal, primitive) tenor of technology.

The development of technological stages is evolutionary and goes from a primitive industry where almost all products are unique, created in accordance with the individual needs of the customer, through the machine stage of production, ensuring a massive offer of similar products, to the individualized mass production, the ability to create products on a mass scale and meet the individual demands of customers. Simple cooperation and division of labor intrinsic to pre-industrial (artisanal) tenor of technology are losing their previously dominant position in the industrial society.

Here the "factory organization" is the most common in the economy. Later, assembly-line production, corresponding to the third and fourth technological stages, takes the leading position. They create the basis for the post-industrial tenors of technology using hard modules (automatic factory) and flexible automated modules, based on the use of standardized components and expensive creative skills of quite few employees. The seventh technological stage is linked to human communication and behavior of machines. 
The functioning of any economy is based on the allocated tenors of technology that serve as a base for creating of regional gross domestic product.

Figure 1: Situational model of tenors of technology monitoring in a national economy

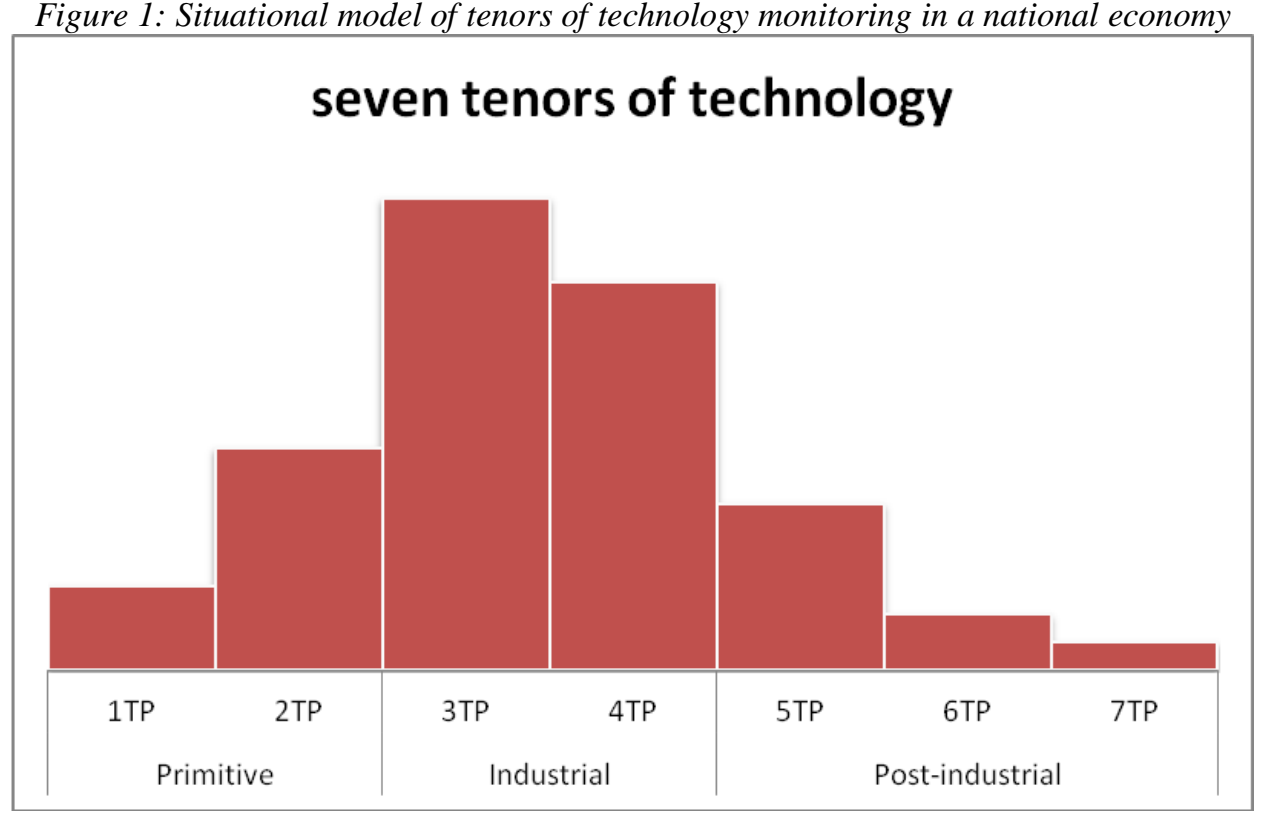

Source: author's compilation according to Department of Marketing and Foresight, MGUTU.

Regional gross domestic product is produced partly within primitive tenors of technology, partly on the basis of industrial tenors of technology, partly on the equipment of postindustrial tenors of technology. Schematically it can be represented as a pyramid. The use of this approach to the agricultural market performance assessment in a region will allow to monitor the development dynamics of new, more advanced tenors of technology. This would reduce the costs of both production and circulation. Shift to the right side of the "pyramid" visually displays that more advanced technological orders are used in the market. We will use this methodology for the analysis of the Russian domestic potato market performance.

The Russian domestic market of potatoes is highly diverse. As a rule, about 30 million tons are yearly collected in Russia, of which are exported about 100 thousand tons. It is known that the annual volume of potato consumption per person makes now about $33 \mathrm{~kg}$. Therefore, a total of about 4.686 million tons of commodity potatoes is required yearly for Russia, with its more than 142 million citizens. Based on the needed consumption volume per person of about $100 \mathrm{~kg}$, the need is about 14- 5 million tons annually. But the country produces a lot more potatoes more than 30 million tons per year! In fact, potatoes are not scarce in Russia. Potato production meets the needs of the population in accordance with the country food safety requirements. However, local retail faces problems with potatoes every spring. Why is the issue of potatoes so acute in spring?

Potato production in Russia has increased considerably in recent years, not in personal production but in SMEs and big agricultural enterprises. In 2006-2014, average share of personal production counted for $63 \%$ of all potato production, share of agricultural enterprises was $26 \%$, and share of the farmer production was $11 \%$. Using this data, in-depth interviews were conducted with these three categories of producers, as well as with experts and consumers (26 respondents in total). As a result, we have found the difference in dominant tenors of technology (table 1). 
Table 1: The tenors of technology (paradigms - TP) in the Russian domestic potato market

\begin{tabular}{lcccc}
\hline Tenors of technology & TP-1 & TP-2 & TP-3 & TP-4 \\
\hline Potato output, big enterprises & & + & + \\
Potato output, SMEs & & + & + \\
Potato output, personal production & + & + & \\
\hline
\end{tabular}

Source: author's compilation according to Lee et al. (2017)

Thus, we receive the following "Pyramid" of technological ways in the contemporary Russian domestic potato market is captured by figure 2 .

Figure 2: The "tenors of technology pyramid" used in production on the domestic potato market

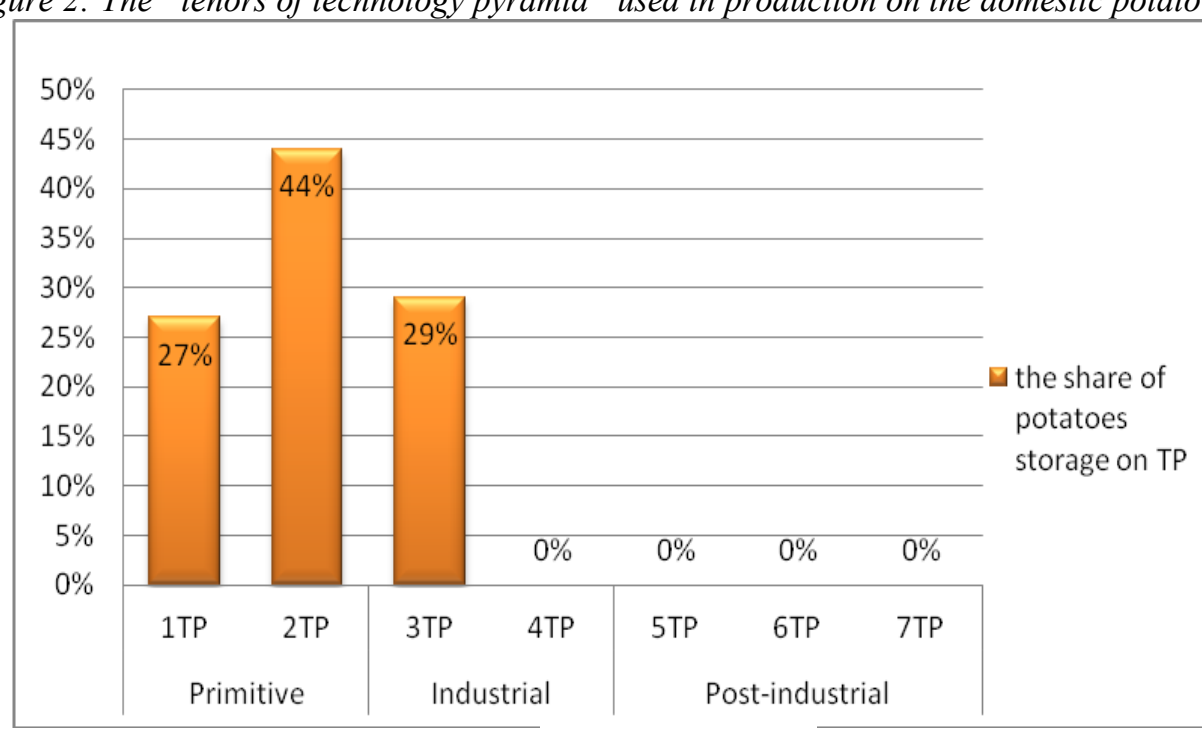

Source: author's compilation according to Tretyak \& Anichkina (2016)

According to the same respondents answering the question "What proportions you assume is necessary to have losses been reduced twice in the domestic potato market?", the "tenors of technology pyramid" in the domestic potato market shall be as follows:

Figure 3: The prospective "tenors of technology pyramid" used in production on the domestic potato market

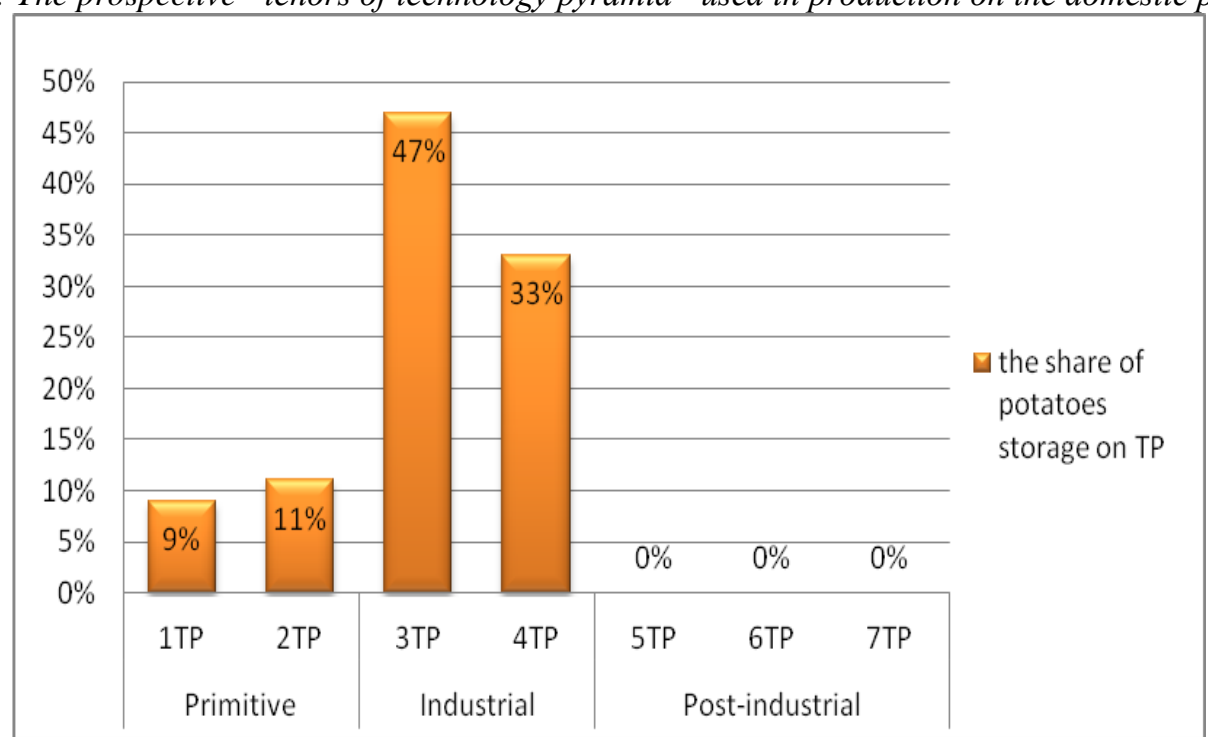

Source: author's compilation according to Santiago-Brown et al. (2015), and Tretyak \& Anichkina (2016) 
Therefore, according to experts, to reduce potato losses twice it is necessary to achieve the shift right side of the "tenors of technology pyramid" used in production on the domestic potato market, in almost the same proportions. Then, productivity is expected to change.

Let us apply similar approach to assessing the performance of potato storage in the Central Federal District (CFD Russia). In-depth interviews with producers, experts and consumers (a total of 26 respondents) were also conducted to unveil the basis of which different techniques are used in the domestic potato storage (Table 2).

If we try to assess the proportion of tenors of technology in potato storage, we can conclude that the harvested potatoes are stored according to different tenors. In most simple storage systems (piles, etc.), up to $44 \%$ potato harvest in CFD is stored in accordance to the first tenor of technology. In stationary storage (bulk or container type) with natural cooling, natural, general exchange of mechanical ventilation or active ventilation, which corresponds to the second tenor of technology, there is about $42 \%$ of the crop. The container type artificial cooling (refrigeration) storage, with mechanical ventilation or active ventilation, which corresponds to the third tenor of technology, approximately $13 \%$ of the crop is kept. The fourth tenor of technology equipment include refrigerators with controlled atmosphere, created by artificial means, as well as storage with a combined cooling - natural and artificial old buildings. Warehousing corresponding to the fourth tenor of technology is virtually absent in CFD. The autonomous double-walled cubes-containers for potato storage, using inert gas, which corresponds to the fifth tenor of technology, and autonomous double-walled cubescontainers with sensors using inert gas, which corresponds to the sixth tenor of technology, no more than $1 \%$ of potato crop is stored as a pilot option (in experimental production). This equipment has no commercial application. The seventh tenor technologies, i.e. potato storage systems with voice setting elements, are also represented only as an experimental option.

Table 2: The used domestic technologies of potato storage system

\begin{tabular}{|c|c|c|c|c|c|c|c|}
\hline Tenors of technology & TP-1 & TP-2 & TP-3 & TP-4 & TP-5 & TP-6 & TP-7 \\
\hline Types of potato storage & & & & & & & \\
\hline The simplest systems of storage & + & & & & & & \\
\hline $\begin{array}{l}\text { Stationary storages with natural cooling, } \\
\text { natural, all-exchange mechanical } \\
\text { ventilation or active aeration. }\end{array}$ & & + & & & & & \\
\hline $\begin{array}{l}\text { Storages of tare type with artificial } \\
\text { cooling. (refrigerators), with all- } \\
\text { exchange mechanical ventilation or } \\
\text { active ventilation. }\end{array}$ & & & + & & & & \\
\hline $\begin{array}{l}\text { Refrigerators with application of the } \\
\text { adjustable gas environments created in } \\
\text { the artificial way as well as storages with } \\
\text { the combined cooling - natural and } \\
\text { artificial old construction. }\end{array}$ & & & & + & & & \\
\hline $\begin{array}{l}\text { Autonomous cubes with double walls - a } \\
\text { box for potato storage with use of inert } \\
\text { gas. }\end{array}$ & & & & & + & & \\
\hline $\begin{array}{l}\text { Autonomous cubes with double walls - a } \\
\text { boxes for potato storage with use of inert } \\
\text { gas with adjustment sensors. }\end{array}$ & & & & & & + & \\
\hline $\begin{array}{l}\text { Autonomous cubes with double walls - a } \\
\text { box for potato storage with use of inert } \\
\text { gas, with sensors and regulated by } \\
\text { operator voice. }\end{array}$ & & & & & & & + \\
\hline
\end{tabular}

Source: author's compilation Lyskova (2017), Malinetskiy (2009), Ozturk \& Karabati (2017)

Based on this data, it is possible to visualize the state of the domestic potatoes storage. The economy of any country operates on the basis of selected technological paradigms. Consequently, the generated gross domestic product is the result of technological paradigms 
functioning. Some part of the gross domestic product is produced on the basis of handicraft paradigms, some part is based on the industrial TP, some part is created according to the postindustrial paradigms. Schematically, it can be represented as a pyramid. The higher technological paradigm results in lower consumption of resources and lower costs.

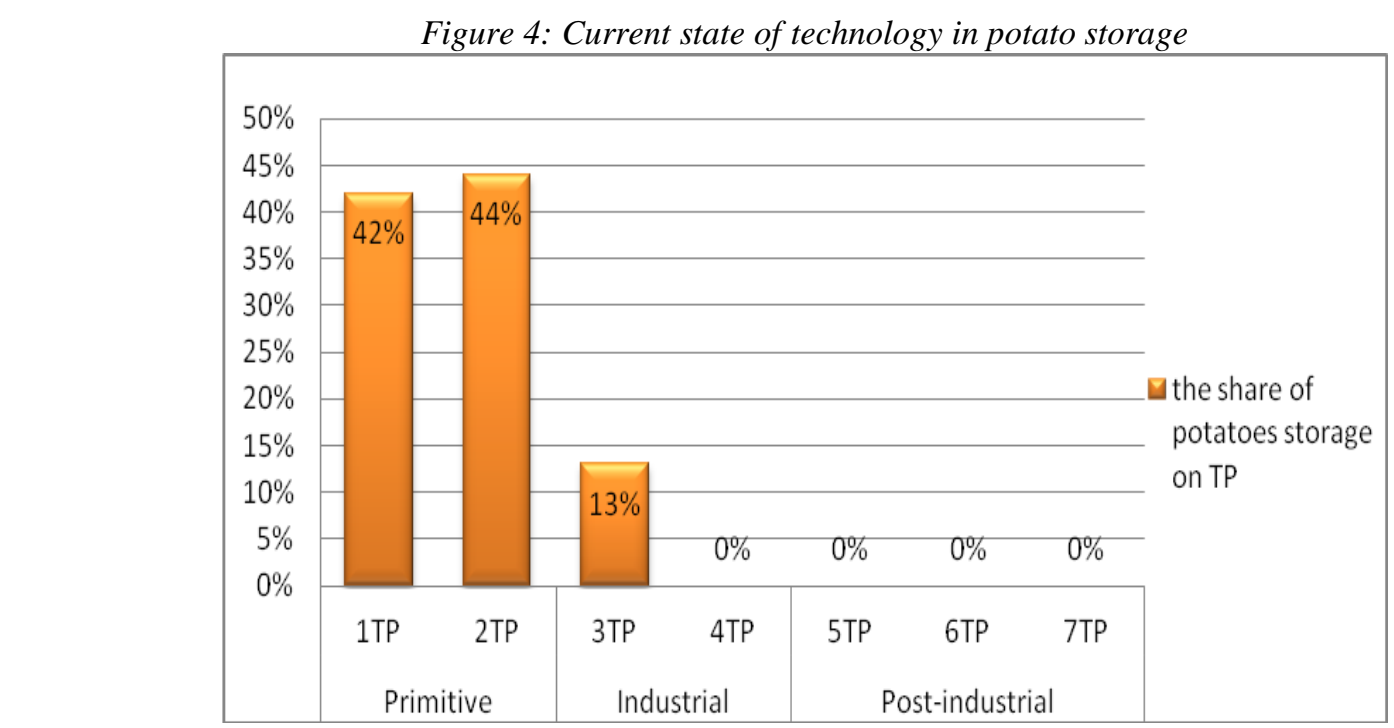

Source: author's compilation according to Tretyak (2016)

Regarding potato storage, it is necessary to focus on the development of storage technologies corresponding to the fifth-sixth-seventh tenors of technology (postindustrial paradigms). It means that Rosagroleasing responsible for agricultural technologies development in Russia should focus its efforts on the acquisition of experimental "cubes", autonomous air-tight containers for the potatoes storage corresponding to fifth-sixth-seventh tenors of technology, and to encourage their use in practice. In addition, an order for the local industry must be formulated to produce domestic analogues of such containers. Besides, the order of the local industry for production of domestic analogs of similar containers should be formulated. Having carried out the list of actions for development post-industrial technologies in the sphere of potato storage, our visual scheme can change. The shares of primitive and industrial tenors of technology will decrease, and the shares of post-industrial technologies in potato storage will increase.

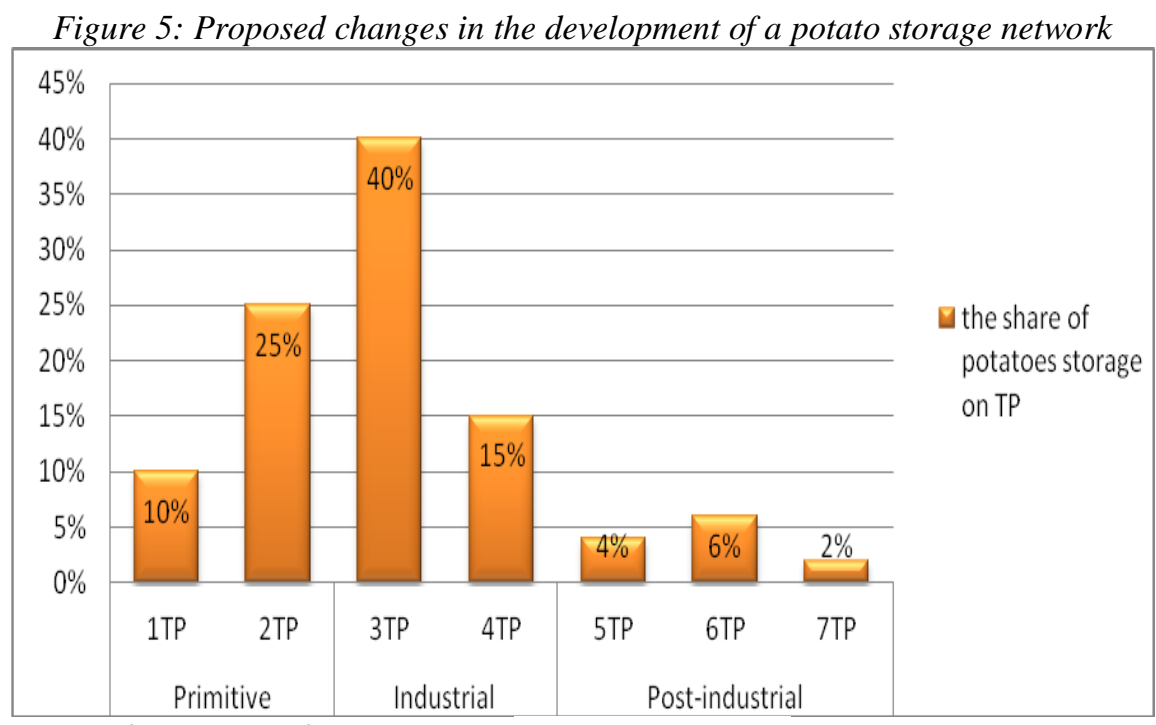

Source: author's compilation according to Tretyak \& Anichkina (2016) 
This transition to post-industrial technology on the Russian potato market will give the chance to decrease the number of expensive storage facilities, to reduce product loss during storage, to increase consumer value of products, and to lower distribution costs. Visually, it will be shown in shift of technology shares "pyramid" in favor of progressive tenors of technology.

\section{Discussion and Conclusion}

In conclusion, it should firstly be noted that the proposed approach to market performance assessment, tested on the Russian domestic potato market, can be an important tool in management of the agricultural market.

Secondly, the proposed approach allows to illustrate visually the extent at which the use of innovative technological solutions and the transition to the highest post-industrial technological stages increases the market performance. In this context, the task of the Ministry of Economic Development of the Russian Federation should not be reduced to annual fixation of poor results of domestic producers and seeking for accusatory factors, explaining and justifying the poor performance of the Ministry itself, not even to how many percent of the agricultural market allow the country to ensure its food safety, but, more importantly, to the development guidelines for the Ministry of agriculture which will help to increase the consistency of the market, improving its performance, as a consequence of the development of post-industrial tenors of technology in both production and circulation.

Thirdly, this approach allows somewhat differently develop state support of local producers. Unless high market performance is seen, state support is unlikely to be provided, since it will lead to an increase in production and distribution costs, and to losses, and the market will not achieve consistency in the foreseeable future. In this case, support from the state becomes plundering, and change of technological stages becomes too slow. State support should be provided to producers aimed at the use of technology related to the post-industrial tenors of technology, since this helps to increase market performance and contributes to its viability growth. But this does not mean that it is necessary to distribute the financial resources before the harvest. Cost structure (salaries, seed, fertilizers, petroleum, equipement maintenance) is quite stable over the years in percentage terms. Still, government support tools can be different. For example, in order to strengthen the production-consumption relationship, «Rosagroleasing» should focus its policy on procurement of equipment for local producers, as well as technological lines for storage and processing. For those market actors that seek to use technology relating to post-industrial technological stages, equipment leasing is important, with granting compensation for the use of post-industrial technologies. Promising tool can be, for example, a special fund sourcing from "poor performance producers", insurance companies and funds allocated by regional authorities to increase market performance.

Fourthly, there is little to produce domestic substitutes with low costs of both production and circulation. It is important to implement these products. But here the question arises, how to reduce the risk of loss in circulation? One of the central elements of the productionconsumption relationship are warehouse distribution centers, providing storage products, product processing enterprises, transportation companies, waste disposal companies. In Soviet times, that was usually isolated independent companies. They functioned under agreements, and mutual claims led to significant growth in distribution costs due to the conflicts between the companies. In modern Russia the situation is gradually changing. The current commodity distribution infrastructure is one of the major barriers to the development of Russian 
agriculture. With the development of retail chains in the domestic market, also wholesale distribution centers as complexes of storage facilities are growing in number. Such distribution centers are a common form of Europe, at least 50 years, their establishment and subsequent development actually take decades.

Therefore, it is necessary to concentrate on stimulation of wholesale distribution centers network development in Russia that will help to considerably reduce distribution costs and will provide domestic producers with access to trade organizations. Then Russian consumers will give preference to local products not only because they are patriotic, but because they count them really better and cheaper due to low distribution costs in domestic distributive networks, and technologies which correspond to higher, post-industrial technological stages.

\section{References}

Abebe, G.K., Bijman, J., Pascucci, S., \& Omta, O. (2013). Adoption of Improved Potato Varieties in Ethiopia: The Role of Agricultural Knowledge and Innovation System and Smallholder Farmers' Quality Assessment. Agricultural Systems, 122, 22-32.

Anigbogu, T.U., Taiwo, A.O. \& Nwachukwu, O.F. (2016). Performance Assessment of Farmers Multipurpose Cooperative Societies (FMCS) in Marketing of Members Farm Produce in Benue State, of Nigeria. Cogent Social Sciences, 2(1), 1219211.

Antonietti, R. \& Marzucchi, A. (2014). Green Tangible Investment Strategies and Export Performance: A FirmLevel Investigation. Ecological Economics, 108, 150-161.

Baggio, R. \& Sheresheva, M.Y. (2014). Network Approach in Economics and Management: The Interdisciplinary Nature. Moscow University Economic Bulletin, 6(2), 3-21.

Bellon, M.R., Gotor, E. \& Caracciolo, F. (2015). Assessing the Effectiveness of Projects Supporting On-Farm Conservation of Native Crops: Evidence from the High Andes of South America. World Development, 70, 162-176.

Bojnec, S. \& Latruffe, L. (2013). Farm Size, Agricultural Subsidies and Farm Performance in Slovenia. Land Use Policy, 32, 207-217.

Bogdanov, N., Rodic, V. \& Vittuari, M. (2017). Structural Change and Transition in the Agricultural Sector: Experience of Serbia. Communist and Post-communist Studies, 50(4), 319-330.

Brenes, E.R., Montoya, D. \& Ciravegna, L. (2014). Differentiation Strategies in Emerging Markets: The Case of Latin American Agribusinesses. Journal of Business Research, 67(5), 847-855.

Caves, R.E. (1992). American Industry. Structure, Conduct, Performance. New Jersey, USA: Prentice-Hall.

Grinciuc, L. \& Bujor, T. (2017). The Impact on the Small Business in the Agricultural Sector in Order to Enhance Competitiveness. Scientific Papers-series Management Economic Engineering in Agriculture and Rural Development, 17(1), 231-234.

Holtermann, S. (1974). Market Structure and Economic Performance in U.K. Manufacturing Industry. Journal of Industrial Economics, 22(2), 119-139.

Hidefjall, P. \& Backheden, M. (2017). Making Health Technology Assessment More Dynamic - Temporal Trend Analysis to Capture Performance Trajectories. Health Policy and Technology, 6(3), 328-338.

Kifli, F.W. \& Umami, A. (2017). Contribution of Economic Sector and Agricultural Development to Support Food Security in North Sumatra Province. Advanced Science Letters, 23(7), 6428-6431.

Kondratiev, N. D. (1989). Problems of economic dynamics. M.: Economics.

Liu, X., Chen, J., Xie, Y. et al. (2016). Strategic Transformation Throught Innovation in Emerging Industry: A Case Study. International Journal of Technology Management, 72(1-3), 192-209.

Lee, K., Park, J. \& Yoon, M. (2017). Industry Dynamics with Diversity in Firms' Catch-Up Strategies and Demand Conditions: A Simulation Approach. Economics of Innovation and New Technology, 26(8), 755778.

Liefert, W. M. \& Liefert, O. (2012). Russian Agriculture during Transition: Performance, Global Impact, and Outlook. Applied Economic Perspectives and Policy, 34(1), 37-75.

Lyskova, L.M. (2017). The Effects of the Increase in Trade Cooperation between Ukraine and EU in Agricultural Sector: Empirical Evaluation. Scientific Bulletin of Polissia, 3, 83-91.

Malinetskiy, G. (2009). Report at the Institute of Dynamic Conservatism Seminar "Real Innovations and Their Simulation in Russia". Main Science and Technology Indicators. OECD, Paris, France.

Perez-Perez, C. (1983). Structural Change and Assimilation of New Technologies in the Economic and Social System. Long Waves in the World Economy, 1-13. 
Ozturk, O.C. \& Karabati, S. (2017). A Decision Support Framework for Evaluating Revenue Perfomayce in Sequential Purchase Contexts. European Journal of Operational Research, 263(3), 922-934.

Rodrigues, M.V., Kureski, R. \& Pereira da Veiga, C. (2016). Assessment of the Economic Structure of Brazilian Agribusiness. The Scientific World Journal, 1-10.

Santiago-Brown, I., Metcalfe, A., Jerram, C. et al. (2015). Sustainability Assessment in Wine-Grape Growing in the New World: Economic, Environmental, and Social Indicators for Agricultural Business. Sustainability, 7(7), 8178-8204.

Scherer, F. \& Ross, D. (2002). Industrial Market Structure and Economic Performance.

Schumpeter, J. (1982). The Theory of Economic Development. N.Y.: Progress, Schumpeter J. A. Business Cycles.

Schierhorn, F., Müller, D., Prishchepov, A.V., Faramarzi, M. \& Balmann, A. (2014). The Potential of Russia to Increase its Wheat Production through Cropland Expansion and Intensification. Global Food Security, 3(3), 133-141.

Tretyak, V. P. (2016). Import Substitution As an Integral Component of Economic Policy. Question mark, 5, 16 $-26$.

Tretyak, V. \& Anichkina, O. (2016). Instruments for the Implementation of Import Substitution Strategy in the Agro-Industrial Complex. Proceedings of the 4th International Conference on Management and Technology in Knowledge, Service, Tourism \& Hospitality.

Trjascin, M. M. (2013). Sustainable Development Management of the Regional Food Market. World Applied Sciences Journal, 23(4), 466-472.

Zinchuk, T., Kutsmus, N., Kovalchuk, O. et al. (2017). Institutional Transformation of Ukraine's Agricultural Sector. Review of Economic Perspectives, 17(1), 57-80. 